www.nature.com/pj

\title{
Properties and curing kinetics of C21-based reactive polyamides as epoxy-curing agents derived from tung oil
}

\begin{abstract}
Kun Huang ${ }^{1,2}$, Jianling Xia ${ }^{1,2,3}$, Xiaohua Yang ${ }^{1}, \mathrm{Mei} \mathrm{Li}^{1}$ and Haiyang Ding ${ }^{1}$
Three $\mathrm{C}_{21}$-based reactive polyamides were synthesized from tung oil and different polyamines. The thermal and mechanical properties of cured products of the $C_{21}$-based polyamides and diglycidyl ether of bisphenol $A$ (DGEBA) were investigated. It was found that the cured materials were superior to those cured by $\mathrm{C}_{36}$-based polyamides in tensile strength and flexural strength and had a better flexural modulus. The glass transition temperatures of the three cured $\mathrm{C}_{21}$-based polyamides, determined by differential scanning calorimetry (DSC), were found to be 108,109 and $116{ }^{\circ} \mathrm{C}$, which were also higher than those of $\mathrm{C}_{36}$-based polyamides. The curing kinetics of $\mathrm{C}_{21}$-based polyamides in the presence of DGEBA were studied by nonisothermal DSC at different heating rates. The kinetic parameters of the curing process were determined by the iso-conversional method given by Málek. A two-parameter $(m, n)$ autocatalytic model (the Šesták-Berggren equation) was found to be the most suitable to describe the curing kinetics of the studied curing agents. The activation energy $\left(E_{\mathrm{a}}\right)$ values of the three curing agents with DGEBA are dependent on the amine values of polyamides. The $E_{\mathrm{a}}$ value of the curing reaction decreased as the primary amine values of curing agents increased. The experimental non-isothermal DSC curves show a good agreement with theoretical calculations.
\end{abstract}

Polymer Journal (2010) 42, 51-57; doi:10.1038/pj.2009.303

Keywords: cure kinetics; differential scanning calorimetry; epoxy resin; mechanical properties; reactive polyamide

\section{INTRODUCTION}

Reactive polyamides of dimer fatty acids are versatile products used as epoxy-curing agents. Most of these reactive polyamides are synthesized using $\mathrm{C}_{36}$ dimer fatty acids and polyamines; their epoxy-curing products are flexible, but have poor thermal resistance and poor rigidity because of the $\mathrm{C}_{36}$ dimer fatty acid's long carboxyl chain. Therefore, the applications of conventional reactive polyamides are limited by their heatresistance and suppleness. To solve this problem, diacid with a shorter carboxyl chain should be used to replace the $\mathrm{C}_{36}$ dimer fatty acid.

In this study, a series of reactive polyamide resins were prepared by a new methyl of $\mathrm{C}_{21}$ diacid made from tung oil and polyamines. Several studies have referred to $C_{21}$ diacid; most of the $C_{21}$ diacids are synthesized by the Diels-Alder reaction of tall oil fatty acids or dehydrated castor oil fatty acids and acrylic acid at a high reactive temperature. ${ }^{1-3}$ The tall oil fatty acid contains about $50 \%$ linoleic acid, which can react with acrylic acid through the Diels-Alder reaction, hence the yield of $\mathrm{C}_{21}$ diacid from tall oil fatty acid is about $50 \%$ by molar. The yield of $\mathrm{C}_{21}$ diacid from dehydrated castor oil fatty acids is about $90 \%$ by molar, but this requires many reaction steps and is thus costly. In addition, because of the unconjugated double bonds of tall oil and dehydrated castor oil fatty acids, a catalyst such as iodine or phosphate is required so that the Diels-Alder reaction can be carried out, and it is difficult to separate the catalyst from the product.

Tung oil fatty acids contain about $85 \%$ eleostearic acid, which has three conjugated double bonds in the molecular backbone. The DielsAlder reaction tends to proceed easily for eleostearic acid molecules that have conjugated double bonds without any catalysts. As a result, the reaction temperature of tung oil fatty acids and acrylic acid is $180^{\circ} \mathrm{C}$, which is much lower than that of the reaction between tall oil fatty acids or dehydrated castor oil fatty acids and acrylic acid (about $250^{\circ} \mathrm{C}$ ). Energy consumption is reduced by using the methyl of tung oil fatty acids to prepare $\mathrm{C}_{21}$ diacid derivatives. In addition, as there is $85 \%$ eleostearic acid in tung oil fatty acids, the yield of $\mathrm{C}_{21}$ diacid is about $85 \%$ by molar.

Reactive polyamides synthesized by $\mathrm{C}_{21}$ diacids were reported by Vijayalakshmi et al., ${ }^{4}$ and it was found that the coating properties of the epoxy-cured materials obtained from $\mathrm{C}_{21}$ diacid were superior to those obtained from the $\mathrm{C}_{36}$ dimer acid in tensile strength and had

${ }^{1}$ Institute of Chemical Industry of Forest Products, Chinese Academy of Forestry, Nanjing, Jiangsu, China; ${ }^{2}$ Key Open Lab. of Forest Chemical Engineering, State Forestry Administration, Nanjing, Jiangsu, China and ${ }^{3}$ Technology Development Corporation of Institute of Chemical Industry of Forest Products, Chinese Academy of Forestry, Nanjing, Jiangsu, China

Correspondence: Professor J Xia, Institute of Chemical Industry of Forest Products, Chinese Academy of Forestry, Suojinwucun No. 16, Nanjing, Jiangsu 210042, China. E-mail: xiajianling@126.com

Received 14 July 2009; revised 31 July 2009; accepted 3 October 2009 
better hardness and adhesion. However, the $\mathrm{C}_{21}$ diacid that was reported by Vijayalakshmi et al. ${ }^{4}$ was synthesized from tall oil fatty acid, but not from tung oil fatty acid. The $\mathrm{C}_{21}$ diacid made from tung oil is a new kind of $\mathrm{C}_{21}$ diacid and has not yet been reported. Furthermore, the curing kinetics of $\mathrm{C}_{21}$ diacid reactive polyamide with epoxy resins have not been previously mentioned in the literature.

The final properties of cured epoxy are intensively dependent on the chemical structure and degree of crosslinking within the polymer network. Thus, it is necessary to be informed of the curing kinetics of the epoxy-curing agent. Curing kinetic parameters are generally determined by analyzing the experimental results obtained by different thermal analysis techniques. ${ }^{5-9}$ Differential scanning calorimetry (DSC), both in the scanning and non-isothermal modes, has been used extensively in this manner. ${ }^{10-14}$

This paper reports the mechanical properties of $\mathrm{C}_{21}$ diacid-based polyamides from tung oil curing DGEBA and curing kinetics based on non-isothermal DSC measurements, applying the simple and consistent method of Málek ${ }^{15-20}$ to the kinetic analysis of data obtained by thermal treatment.

\section{EXPERIMENTAL PROCEDURE}

\section{Materials}

Tung oil (Figure 1a) that was converted into methyl fatty acids and analyzed by gas chromatography-mass spectrometry was obtained from Wuxi Jinyu Oil Corporation (Wuxi City, Jiangsu Province, China). Methyl eleostearate makes up $85.5 \%$ of the methyl of fatty acids, according to gas chromatography mass spectrometry results.

Methyl eleostearate was obtained by transesterification of tung oil and methanol. ${ }^{21}$ The methyl of $\mathrm{C}_{21}$ diacid (Figure $1 \mathrm{~b}$ ) was prepared by the DielsAlder reaction of methyl eleostearate with acrylic acid. DGEBA was obtained from the Wuxi Resin Factory (Wuxi City, Jiangsu Province, China) with an epoxy equivalent weight of 196.

\section{Characterization}

Fourier transform infrared spectra were recorded using a Nicolet 550 infrared spectrometer (Nicolet Corp., Madison, WI, USA) in the range of 500$4000 \mathrm{~cm}^{-1}$ on $\mathrm{KBr}$ pellets.

With $\mathrm{CDCl}_{3}$ solvent, ${ }^{1} \mathrm{H}$ nuclear magnetic resonance $\left({ }^{1} \mathrm{H}\right.$ NMR) spectra were recorded on a Bruker DPX-300 NMR (Bruker Corp., Beijing, China), and tetramethylsilane was used as the internal standard. The operating parameters for ${ }^{1} \mathrm{H}$ NMR were as follows: sweep width, $300 \mathrm{MHz}$; pulse width, $5.80 \mathrm{~ms}$; number of scans, 16

\section{Synthesis}

Here, the typical procedure for the preparation of $\mathrm{C}_{21}$ diacid-based reactive polyamide (Figure $1 \mathrm{c}$ ) is described. Methyl of $\mathrm{C}_{21}$ diacid $(100 \mathrm{~g})$ was placed in a $500 \mathrm{ml}$, four-necked round-bottom flask equipped with a stirrer, a nitrogen inlet tube, a thermometer and a Dean-Stark apparatus. After heating to $140{ }^{\circ} \mathrm{C}$ in $0.5 \mathrm{~h}$, the required quantity of polyamine was added dropwise over a period of $1.5 \mathrm{~h}$. The temperature was then gradually increased to $200{ }^{\circ} \mathrm{C}$ over a period of $1.5 \mathrm{~h}$, and the reaction was continued at this temperature for a further $3 \mathrm{~h}$. The water and methanol liberated during the reaction were collected in the Dean-Stark apparatus. The reaction was monitored by determining the acid a

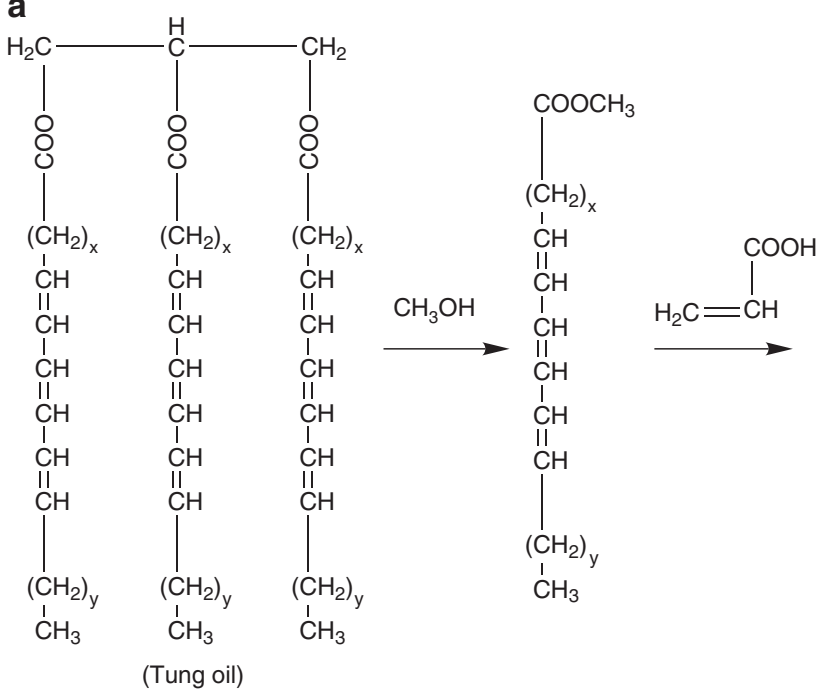

b

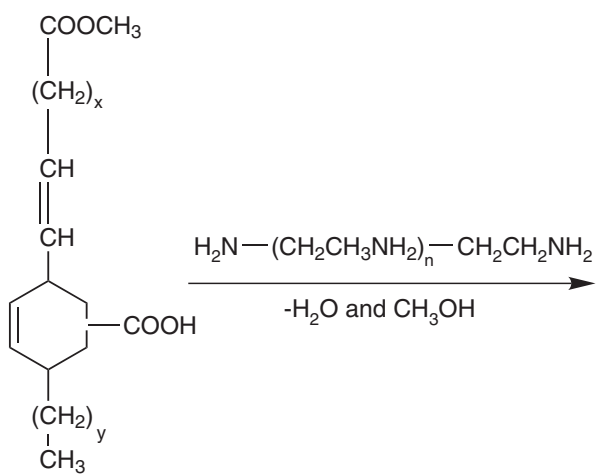<smiles>[Y20][R10]#[Y10][H]</smiles>

Figure 1 Synthesis of $\mathrm{C}_{21}$-based reactive polyamide. (a) Tung oil converted into methyl fatty acids. (b) Methyl of $\mathrm{C} 21$ diacid. (c) $\mathrm{C} 21$ diacid-based reactive polyamide. 
values. When the acid value of the product decreased below $1 \mathrm{mgg}^{-1}$, nitrogen supply was discontinued and volatiles were removed under vacuum $(0.67-$ $1.33 \mathrm{kPa}$ ) for $1 \mathrm{~h}$; the product was then cooled and stored. The steps involved in the preparation are shown in Figure 1.

\section{Sample preparation}

Epoxy resin DGEBA and the $\mathrm{C}_{21}$-based reactive polyamide were carefully and homogenously mixed at the optimum ratio. Samples of 3-4 mg were separated from the freshly prepared compositions for calorimetric measurements. Samples for mechanical property tests were prepared by molding the epoxy mixtures in iron molds, and samples were cured in a vacuum oven using a defined cure program.

\section{Methods}

The mechanical properties of cured materials were examined using a CMT4303 Sans testing machine (Sans Corp., Shenzhen City, Guangdong Province, China) according to standards as follows:

Tensile strength, tensile strain and tensile modulus were tested following GB/ T 2568-1995. The bending strength and modulus were tested following GB/T 2570-1995. Compression strength was examined following GB/T 2569-1995 and lap shear strength was tested following GB 7124-86.

Differential scanning calorimetry experiments were run on a Perkin-Elmer Diamond DSC calorimeter (Perkin-Elmer Corp., Waltham, MA, USA) to analyze data. Samples were placed in an aluminum pan and then covered by an aluminum lid before undergoing a specific cure program, depending on the mode of measurement. Scanning DSC measurements were carried out at four heating rates of $5,10,20$ and $40{ }^{\circ} \mathrm{C} \mathrm{min}{ }^{-1}$ from 30 to $250^{\circ} \mathrm{C}$ in a nitrogen atmosphere. Pure indium was used as the standard for calorimetric calibration. Runs were carried out using an empty cell as reference. Heat flow data, as a function of temperature and time, were obtained using the area under the peak of the exothermal. These data were processed further to obtain the fractional conversion and rate of reaction. Raw data were converted into Excel files and then kinetic analysis was applied.

The basic assumption for the application of the DSC technique to the curing of thermosetting polymers is that the rate of the kinetic process $(\mathrm{d} \alpha / \mathrm{d} t)$ is proportional to the measured heat flow $\phi .^{18,20}$

$$
\frac{\mathrm{d} \alpha}{\mathrm{d} t}=\frac{\phi}{\Delta H}
$$

where $\Delta H$ is the enthalpy of the curing reaction.

The rate of the kinetic process in kinetic analysis can be described by Equation (2)

$$
\frac{\mathrm{d} \alpha}{\mathrm{d} t}=k(T) f(\alpha)
$$

where $k(T)$ is a temperature-dependent reaction rate constant and $f(\alpha)$ is a mechanism-dependent kinetic model function..$^{20,21}$

The rate constant is dependent on temperature as shown in Equation (3)

$$
k(T)=A \exp \left(-E_{\mathrm{a}} / R T\right)
$$

where $A$ is the preexponential factor, and $E_{\mathrm{a}}$ is the apparent activation energy.

The kinetic parameters of the curing reaction, with special reference to $E_{\mathrm{a}}$, can be calculated using various computational methods. ${ }^{22,23}$ Activation energy was determined by the iso-conversion method, ${ }^{16}$ using the logarithmic form of the kinetic rate (Equation (2))

$$
\ln \frac{\mathrm{d} \alpha}{\mathrm{d} t}=\ln [A f(\alpha)]-\frac{E_{\mathrm{a}}}{R T}
$$

The slope of $\ln (\mathrm{d} \alpha / \mathrm{d} t)$ versus $1 / T$ for the same value of $\alpha$ gives the value of $E_{\mathrm{a}}$. The value of $E_{\mathrm{a}}$ can then be used to find the appropriate kinetic model that best describes the conversion function of the studied process. For this, it is necessary to appeal to the special functions, $y(\alpha)$ and $z(\alpha) .{ }^{15,16}$

$$
\begin{aligned}
& y(\alpha)=\left(\frac{\mathrm{d} \alpha}{\mathrm{d} t}\right) e^{x} \\
& z(\alpha)=\pi(x)\left(\frac{\mathrm{d} \alpha}{\mathrm{d} t}\right) \frac{T}{\beta}
\end{aligned}
$$

where $x$ is the reduced activation energy $\left(E_{\mathrm{a}} / \mathrm{RT}\right), \beta$ is the heating rate $\left(\mathrm{K} \min ^{-1}\right), T$ is the absolute temperature $(\mathrm{K})$ and $\pi(x)$ is the expression of the temperature integral. As pointed out previously, ${ }^{15}$ the $\pi(x)$ function can be well approximated using the fourth rational expression of Senum and Yang ${ }^{24}$ as in Equation (7)

$$
\pi(x)=\frac{x^{3}+18 x^{2}+88^{x}+96}{x^{4}+20 x^{3}+120 x^{2}+240 x+120}
$$

Function $y(\alpha)$ is proportional to $f(\alpha)$ function, being characteristic for a given kinetic model. The shape and maximum of both $y(\alpha)$ and $f(\alpha)$ functions for several models, normalized within the $(0,1)$ interval, provide valuable information for determining the most suitable kinetic model to characterize the process studied.

\section{RESULTS AND DISCUSSIONS}

\section{Apparent properties of reactive polyamides}

Reactive polyamides having amine values ranging from 374 to 496 were prepared by reacting the $\mathrm{C}_{21}$ diacid with different polyamines, such as diethylene triamine, triethylene tetramine and tetraethylene pentamine, at two different molar ratios (1:1.2 and 1:1.5). Polyamides were prepared from the $\mathrm{C}_{36}$ dimer acid and diethylene triamine (in the mole ratio 1:2) for comparison. The apparent properties of these polyamides are given in Table 1.

The data in Table 1 show that the polyamides with lower amine values have higher viscosities than those with higher amine values because of their lower molecular weights. Polyamides derived from $\mathrm{C}_{36}$ dimer acids are lighter in color than those derived from the methyl of $\mathrm{C}_{21}$ diacid.

Figure 2 shows the ${ }^{13} \mathrm{C}-\mathrm{NMR}$ spectra of the methyl of $\mathrm{C}_{21}$ diacid (Figure 1b). The peaks at $\delta 14.1,51.5,174.5$ and 181.7 can be assigned to $-\mathrm{CH}_{3},-\mathrm{OOCH}_{3},-\mathrm{COO}-$ and $-\mathrm{COOH}$, respectively. Peaks from $\delta$ $22.9-43.5$ can be attributed to methylene $\left(-\mathrm{CH}_{2}-\right)$. Peaks at $\delta 127.4$ and 128.3 can be assigned to cyclohexene (

Figures $3 \mathrm{a}-\mathrm{c}$ show the Fourier transform infrared spectra of methyl eleostearate and (a) acrylic acid, (b) $\mathrm{C}_{21}$ diacid and (c) $\mathrm{C}_{21}$-based reactive polyamide, respectively. For (a), the reactant acrylic acid was confirmed by the appearance of $\mathrm{C}=\mathrm{C}$ stretching and vibration absorption peaks at 1635,966 and $993 \mathrm{~cm}^{-1}$, and in product (b) these peaks disappeared. The methyl of $\mathrm{C}_{21}$ diacid (b) was already confirmed by ${ }^{13} \mathrm{C}-\mathrm{NMR}$, as shown in Figure 2 . Figure $3 \mathrm{c}$ shows the $\mathrm{C}_{21}$-based polyamide's structure. The condensation reaction between the methyl of $\mathrm{C}_{21}$ diacid (b) and polyamines was confirmed by the appearance of a $\mathrm{C}=\mathrm{O}$ stretching absorption peak at $1650 \mathrm{~cm}^{-1}$, as well as by the appearance of a strong broad characteristic absorption peak of $-\mathrm{N}-\mathrm{H}$ stretching vibration at $3280 \mathrm{~cm}^{-1}$ and that of an absorption peak of $\mathrm{C}-\mathrm{N}$ stretching vibration at $1120 \mathrm{~cm}^{-1}$.

\section{Glass transition temperature and mechanical properties}

The glass transition temperatures of cured DGEBA for samples 1-4 were measured by DSC. The results are shown in Figure 4. The glass transition temperatures of the four samples were found to be 53,108 ,

Table 1 Properties and sample numbers of curing agents derived from different monomers

\begin{tabular}{llcccc}
\hline Sample & Diacids:amines & $\begin{array}{c}\text { Total amine } \\
\text { value }\left(\mathrm{mgg}^{-1}\right)\end{array}$ & $\begin{array}{c}\text { Primary amine } \\
\text { value }\left(\mathrm{mgg}^{-1}\right)\end{array}$ & $\begin{array}{c}\text { Color } \\
\text { (mPas) }\end{array}$ \\
\hline 1 & $\mathrm{C}_{21}: \mathrm{DETA}=1: 2$ & 374 & 115 & 14 & 32700 \\
2 & $\mathrm{C}_{21}: \mathrm{TETA}=1: 1.5$ & 419 & 76 & 13 & 17834 \\
3 & $\mathrm{C}_{21}: \mathrm{TEPA}=1: 2$ & 496 & 98 & 13 & 12100 \\
4 & $\mathrm{C}_{36}: \mathrm{DETA}=1: 2$ & 210 & 42 & 10 & 40100 \\
\hline
\end{tabular}




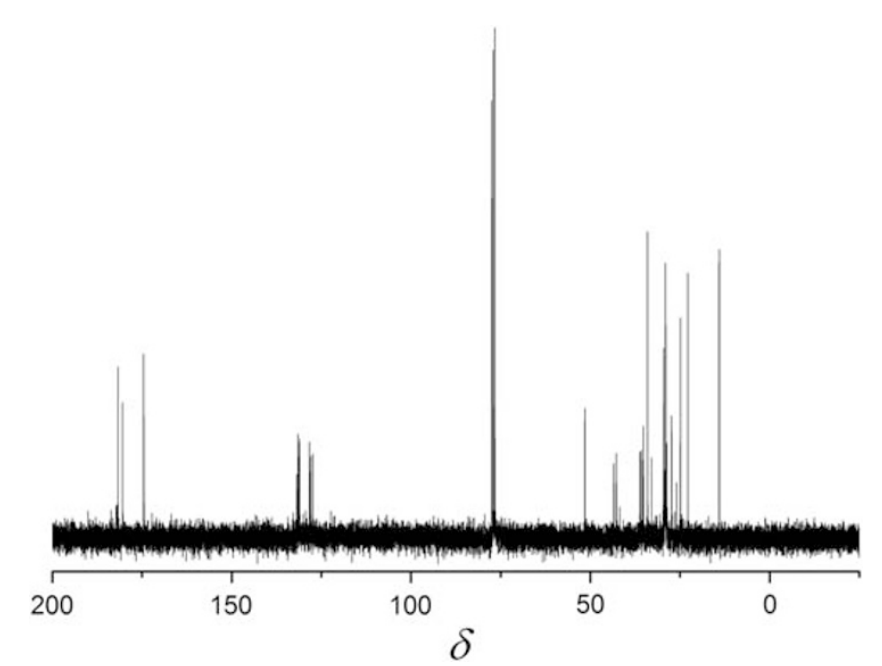

Figure $2{ }^{13} \mathrm{C}-\mathrm{NMR}$ spectra of the methyl of $\mathrm{C}_{21}$ diacid.

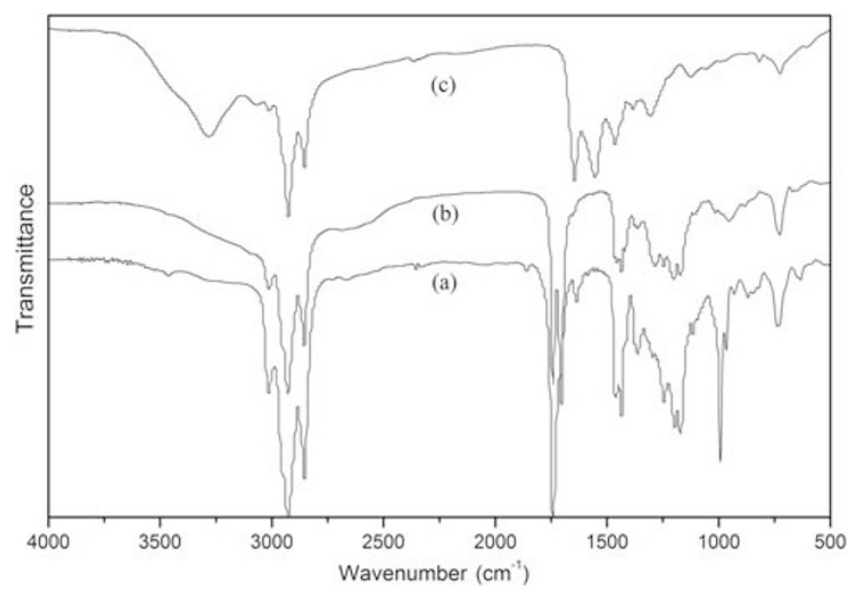

Figure 3 Fourier transform infrared spectra of reactants and products, methyl eleostearate and acrylic acid (a); $\mathrm{C}_{21}$ diacid (b) and C21-based reactive polyamide (c).

109 and $116^{\circ} \mathrm{C}$, respectively. The glass transition temperature of the cured resin increased as the amine value increased; this might be because of the increasing crosslink density and polarity of polyamides. The glass transition temperature of $\mathrm{C}_{21}$-based polyamides is about twice that of the $\mathrm{C}_{36}$-based polyamide because of shorter molecular chains in $\mathrm{C}_{21}$-based polyamides.

The mechanical strength and modulus were tested by a Sans testing machine. The tensile strength and strain are shown in Figure 5. As the amine values of samples increased from samples 1 to 3 , tensile strength increased. However, sample 4 was found to be more flexible than the C21-based polyamide-cured resins, because it had a low tensile strain, similar to that of sample $3 . \mathrm{C}_{21}$-based polyamides tend to be hard and rigid, whereas $\mathrm{C}_{36}$-based polyamides are more flexible. The flexural strengths of the four samples are shown in Figure 6. By increasing amine values, the flexural strength and modulus increased significantly. This is because of the increased crosslink density of the polymers.

The shear strength, thermal deformation temperature and shore D hardness values are shown in Table 2. Shear strength is strongly dependent on the flexibility of the polyamide backbone. Owing to the shorter and more rigid molecular chain in $\mathrm{C}_{21}$-based polyamides,

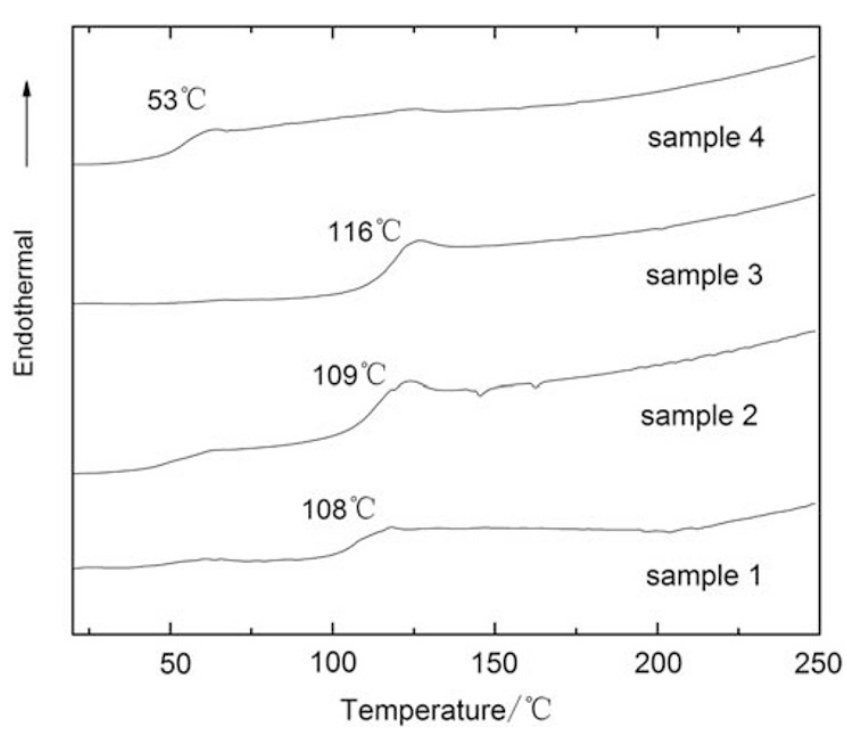

Figure 4 Differential scanning calorimetry curves for the glass transition temperatures of cured diglycidyl ether of bisphenol $A$.

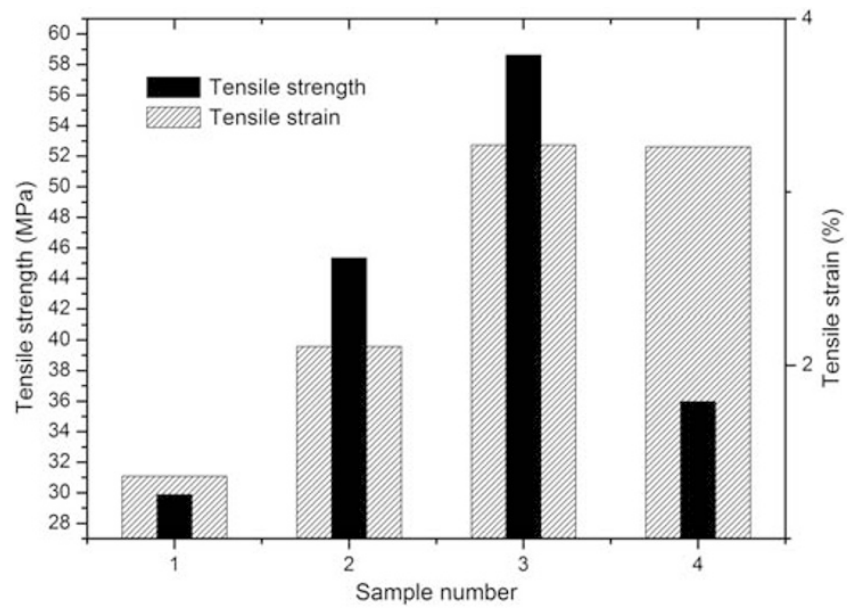

Figure 5 Tensile strength and strain of the polyamide/diglycidyl ether of bisphenol A system.

their shear strengths are lower than those of $\mathrm{C}_{36}$-based polyamides. As amine values increased, crosslink density increased, producing a more rigid polyamide backbone. Thus, the shear strength was increased by raising the amine values of polyamides. The thermal deformation temperature and shore $\mathrm{D}$ hardness values have the same trend as the glass transition temperature.

\section{Curing kinetics}

Dynamic DSC scans for mixtures of $\mathrm{C}_{21}$-based polyamides and DGEBA were collected at different heating rates $(5,10,20$ and $\left.40{ }^{\circ} \mathrm{C} \mathrm{min}-1\right)$. Typical DSC curves for sample 2 are presented in Figure 7. Similar results were found for the other $\mathrm{C}_{21}$-based polyamides with different amine values. As can be seen in Figure 7 and the resulting exotherm, the rate of curing reaction increases with increasing temperature.

Figure 8 plots the conversion against the dynamic cure temperature at various heating rates. It shows that, at the same conversion, the iso-conversion temperature increases when the heating rate is increased. Plots of cure rate versus cure temperature are shown in 


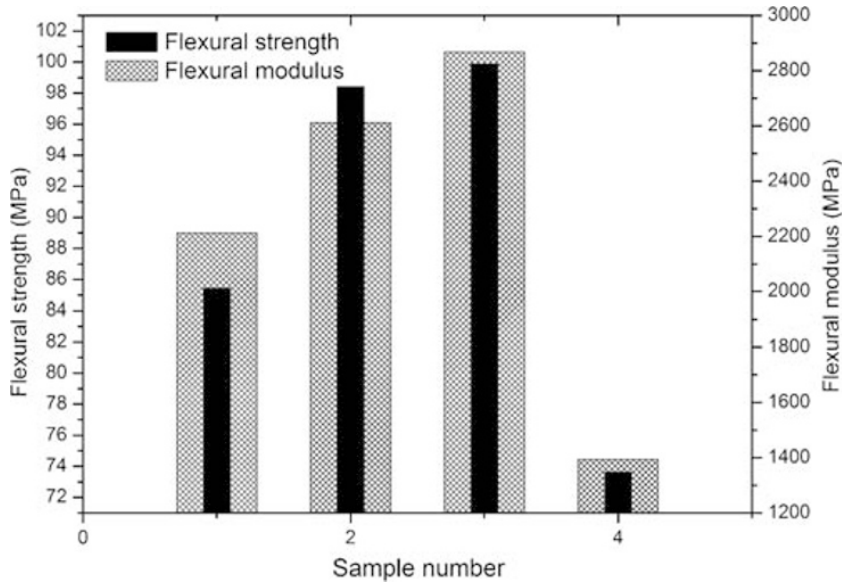

Figure 6 Flexural strength and modulus of the polyamide/diglycidyl ether of bisphenol A system.

Table 2 Properties of four samples cured diglycidyl ether of bisphenol A

\begin{tabular}{lccc}
\hline $\begin{array}{l}\text { Sample } \\
\text { number }\end{array}$ & $\begin{array}{c}\text { Shear strength } \\
(\mathrm{MPa})\end{array}$ & $\begin{array}{c}\text { Thermal deformation } \\
\text { temperature }\left({ }^{\circ} \mathrm{C}\right)\end{array}$ & $\begin{array}{c}\text { Shore } \mathrm{D} \\
\text { hardness }\end{array}$ \\
\hline 1 & 10.62 & 99.5 & 86.1 \\
2 & 9.4 & 93.3 & 85.9 \\
3 & 9.49 & 104.8 & 86.1 \\
4 & 15.83 & 58.8 & 82.5 \\
\hline
\end{tabular}

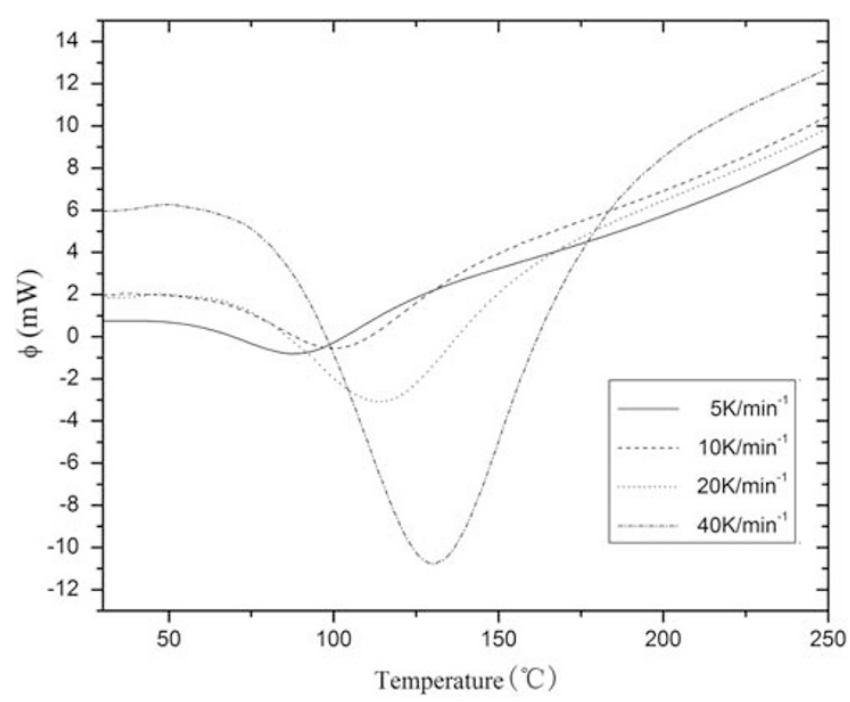

Figure 7 Typical differential scanning calorimetry curves recorded for the sample 2/diglycidyl ether of bisphenol A system at different heating rates.

Figure 9. The cure rate passes through a maximum point and decreases as a function of the curing time. Furthermore, the peak cure rate increases with increasing cure temperature.

Plots of $\ln (\mathrm{d} \alpha / \mathrm{d} t)$ versus $1 / T$ at different conversions are shown in Figure 10. The fractional activation energy for the conversion from 0.1 to 0.9 can be calculated from the slope, on the basis of Equation (4).

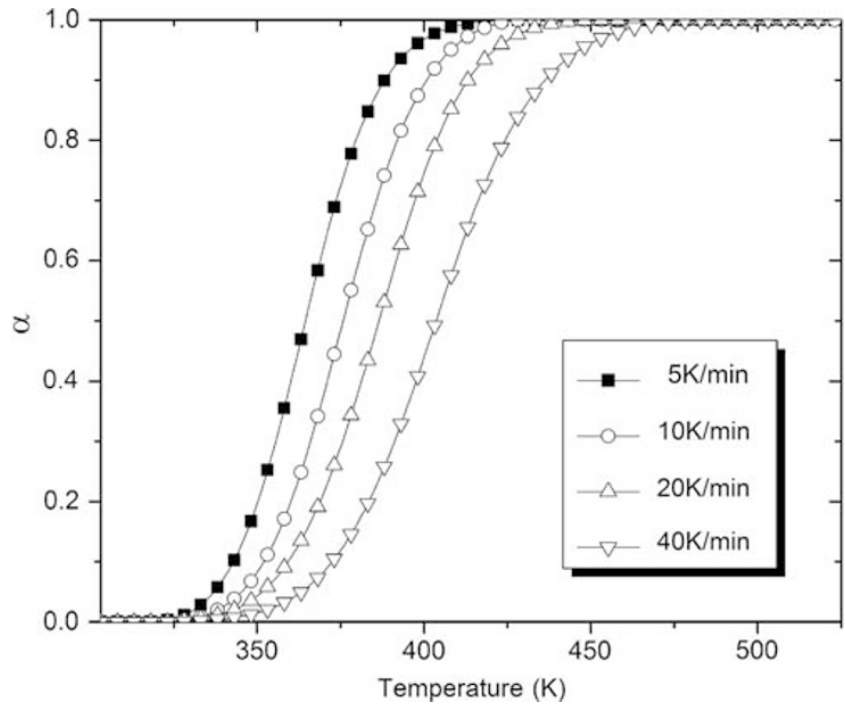

Figure 8 Conversion as a function of temperature for the sample 2/diglycidyl ether of bisphenol A system.

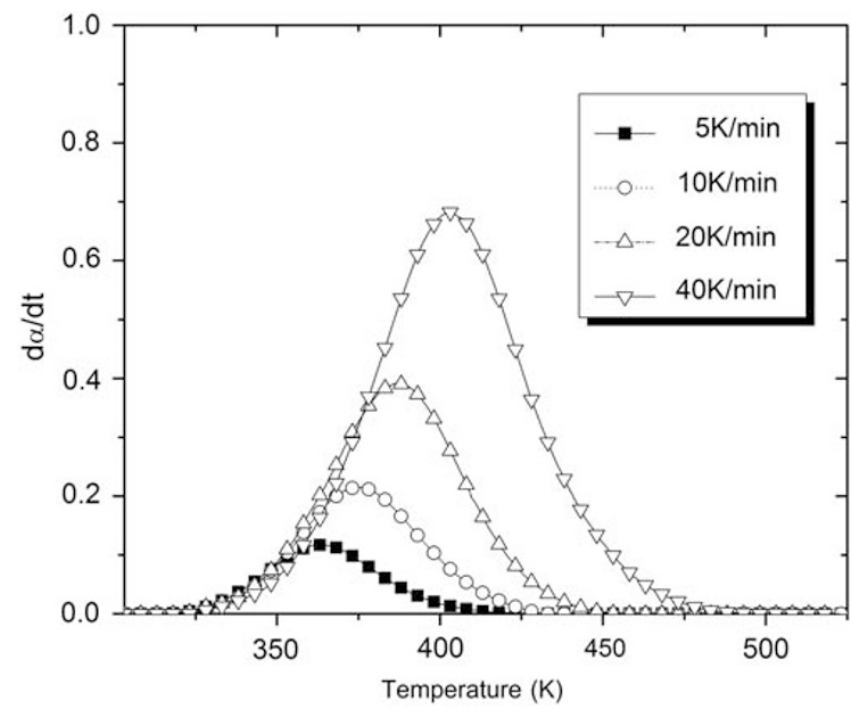

Figure 9 The kinetic rate as a function of temperature for the sample 2/ diglycidyl ether of bisphenol A system.

These results are summarized in Table 3. Arrhenius plots from DSC scans recorded for cured samples using Equation (4) and the same $\alpha$-value are straight lines, the slopes of which give the value of $E_{\mathrm{a}}$. Figure 9 shows the plot obtained for sample 2, in the interval of $0.1<\alpha<0.9$, whereas Figure 11 shows the variation of $E_{\mathrm{a}}$ for all studied samples as a function of the conversion. Figure 11 plots the values of the activation energy for different values of conversion, showing that $E_{\text {a }}$ gradually increases at the early stage of the reaction. This may be because of consumption of the accelerator and a decrease in the mobility of the reactive groups of the partially cured epoxy. The value of $E_{\mathrm{a}}$ is roughly constant in the interval of $0.2<\alpha<0.8$, with a slight tendency to increase or decrease for $\alpha$-values beyond the abovementioned interval. These changes are probably due to errors in the baseline approximation for peak tails, which lead to high error levels in the calculated activation energy. ${ }^{25}$ It is well known that primary amine is more reactive than secondary amine. It can be observed that 


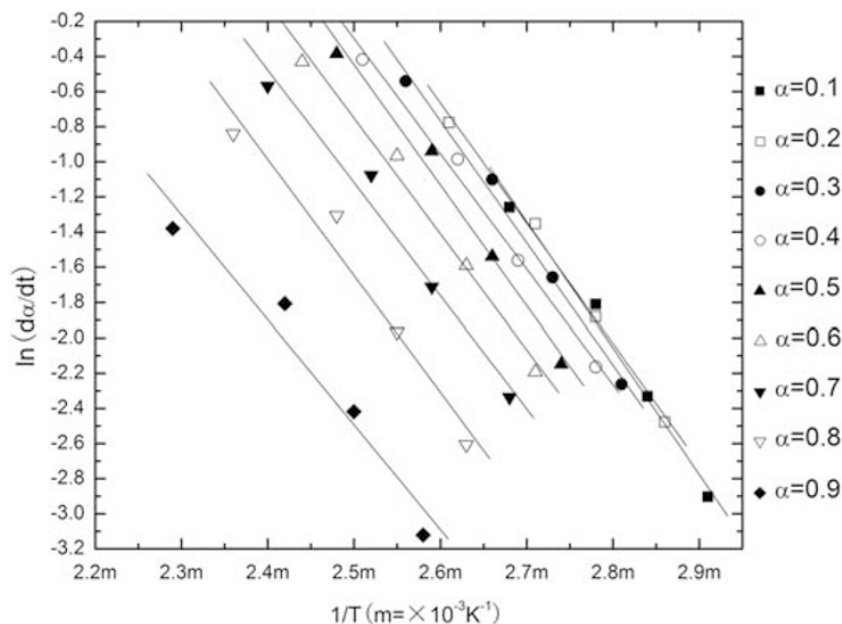

Figure 10 Arrhenius plots for sample 2 in the interval of $0.1<\alpha<0.9$.

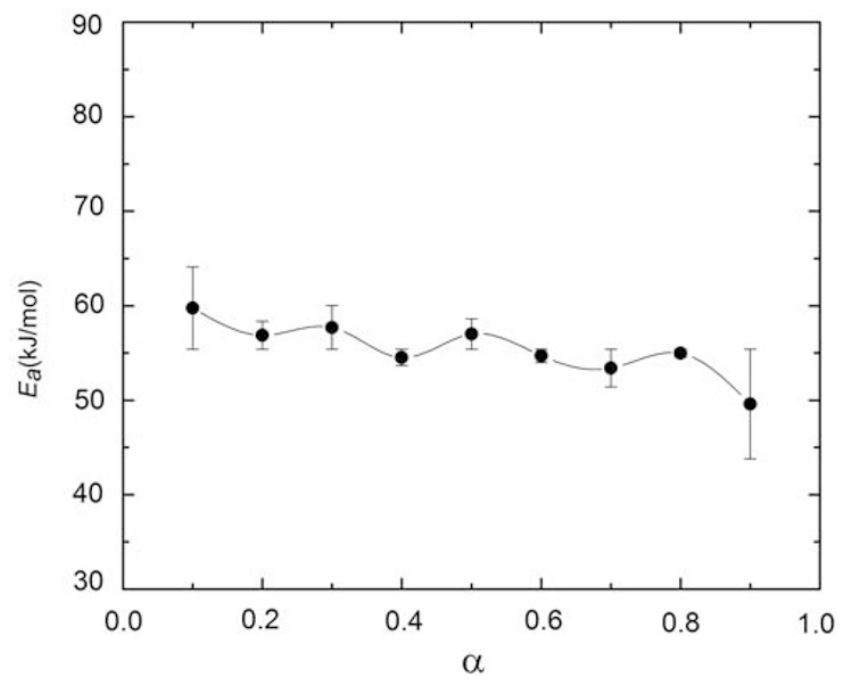

Figure 11 Variation of $E_{\mathrm{a}}$ versus conversion for sample 2 in the interval of $0.1<\alpha<0.9$.

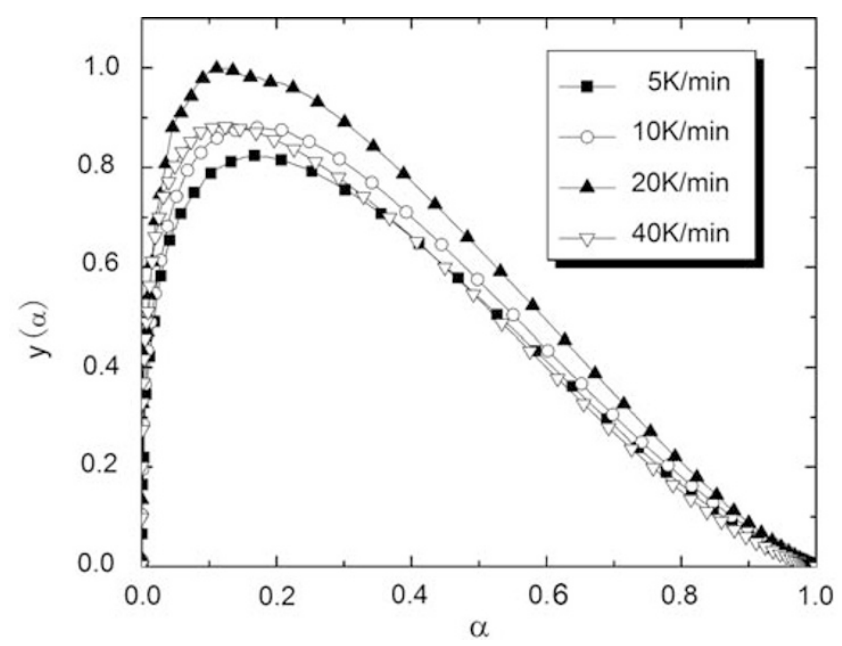

Figure 12 Variation of the $y(\alpha)$ function versus conversion for sample 2.

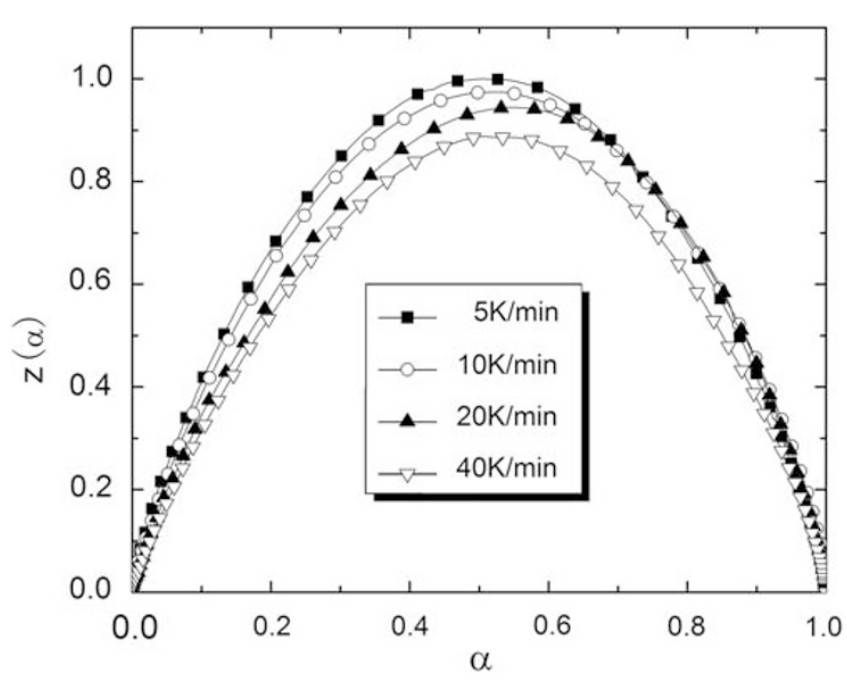

Figure 13 Variation of the $z(\alpha)$ function versus conversion for sample 2 .

Table 3 The kinetics parameters of three samples

\begin{tabular}{|c|c|c|c|c|c|c|c|c|c|}
\hline Sample & $\mathrm{E}_{a}$ & $\begin{array}{c}\beta \\
\left(K / \mathrm{min}^{-1}\right)\end{array}$ & $\mathrm{P}$ & $\begin{array}{c}A \\
\left(\mathrm{~min}^{-1}\right)\end{array}$ & Mean & $\mathrm{n}$ & Mean & $\mathrm{m}$ & Mean \\
\hline \multirow[t]{4}{*}{1} & \multirow[t]{4}{*}{52.4} & 5 & 0.28 & $7.00 \times 10^{6}$ & \multirow[t]{4}{*}{$7.94 \times 10^{6}$} & 0.944 & \multirow[t]{4}{*}{1.064} & 0.264 & \multirow[t]{4}{*}{0.251} \\
\hline & & 10 & 0.25 & $7.68 \times 10^{6}$ & & 1.102 & & 0.276 & \\
\hline & & 20 & 0.22 & $8.37 \times 10^{6}$ & & 1.121 & & 0.247 & \\
\hline & & 40 & 0.20 & $8.72 \times 10^{6}$ & & 1.090 & & 0.218 & \\
\hline \multirow[t]{4}{*}{2} & \multirow[t]{4}{*}{55.4} & 5 & 0.20 & $2.18 \times 10^{7}$ & \multirow[t]{4}{*}{$2.32 \times 10^{7}$} & 1.093 & \multirow[t]{4}{*}{1.082} & 0.219 & \multirow[t]{4}{*}{0.184} \\
\hline & & 10 & 0.20 & $2.31 \times 10^{7}$ & & 1.030 & & 0.206 & \\
\hline & & 20 & 0.14 & $2.48 \times 10^{7}$ & & 1.049 & & 0.147 & \\
\hline & & 40 & 0.14 & $2.32 \times 10^{7}$ & & 1.157 & & 0.162 & \\
\hline \multirow[t]{4}{*}{3} & \multirow[t]{4}{*}{54.4} & 5 & 0.23 & $1.36 \times 10^{7}$ & \multirow[t]{4}{*}{$1.43 \times 10^{7}$} & 1.051 & \multirow[t]{4}{*}{1.087} & 0.242 & \multirow[t]{4}{*}{0.193} \\
\hline & & 10 & 0.18 & $1.37 \times 10^{7}$ & & 1.092 & & 0.197 & \\
\hline & & 20 & 0.16 & $1.49 \times 10^{7}$ & & 1.105 & & 0.177 & \\
\hline & & 40 & 0.14 & $1.50 \times 10^{7}$ & & 1.098 & & 0.154 & \\
\hline
\end{tabular}

sample 1, with the highest primary amine value (Table 1), has the lowest activation energy (Table 3 ). This further demonstrates that sample 1 has a higher reactivity than the other two samples.

The value of $E_{\mathrm{a}}$ was used to calculate both $y(\alpha)$ and $z(\alpha)$ functions using Equations (2) and (6), respectively. Figures 12 and 13 show the variation of $y(\alpha)$ and $z(\alpha)$ versus conversion. Table 4 lists the maxima values $\alpha_{M}$ and $\alpha_{p}^{\infty}$ corresponding to functions $y(\alpha)$ and $z(\alpha)$ for all studied samples.

As noted, the data in Figures 12 and 13 and those in Table 4 show that the values of $\alpha_{M}$ are lower than those of $\alpha_{p}^{\infty}$, whereas the values of $\alpha_{p}^{\infty}$ are lower than 0.632 . This indicates that the studied curing process can be described using the two-parameter autocatalytic kinetic ŠstákBerggren model (Equation (9)). ${ }^{26}$

$$
f(\alpha)=\alpha^{m}(1-\alpha)^{n}
$$

where $m$ and $n$ are the kinetic exponents. ${ }^{16}$

The kinetic exponent $n$ can be obtained by the slope of $\ln \left[(\mathrm{d} \alpha / \mathrm{d} t) e^{x}\right]$ versus $\ln \left[\alpha^{p}(1-\alpha)\right]$ (from Equation (2)), and $m=p n$, where $p=\alpha_{M} / 1-\alpha_{M}$.

Table 3 lists some kinetic parameters evaluated for the proposed Šesták-Berggren kinetic model. As shown in Table 3, the variation of kinetic parameter values with the heating rate is within the experimental error limit (within 10\% of the average value). 
Table 4 The values of $\alpha_{M}$ and $\alpha_{p}^{\infty}$ for each sample

\begin{tabular}{|c|c|c|c|c|c|c|}
\hline \multirow[b]{2}{*}{$\beta\left(K \min ^{-1}\right)$} & \multicolumn{3}{|c|}{$\alpha_{M}$} & \multicolumn{3}{|c|}{$\alpha_{p}^{\infty}$} \\
\hline & Sample 1 & Sample 2 & Sample 3 & Sample 1 & Sample 2 & Sample 3 \\
\hline 5 & 0.22 & 0.17 & 0.19 & 0.51 & 0.50 & 0.57 \\
\hline 10 & 0.20 & 0.17 & 0.15 & 0.53 & 0.53 & 0.53 \\
\hline 20 & 0.18 & 0.12 & 0.14 & 0.53 & 0.55 & 0.52 \\
\hline 40 & 0.17 & 0.12 & 0.12 & 0.52 & 0.51 & 0.54 \\
\hline
\end{tabular}

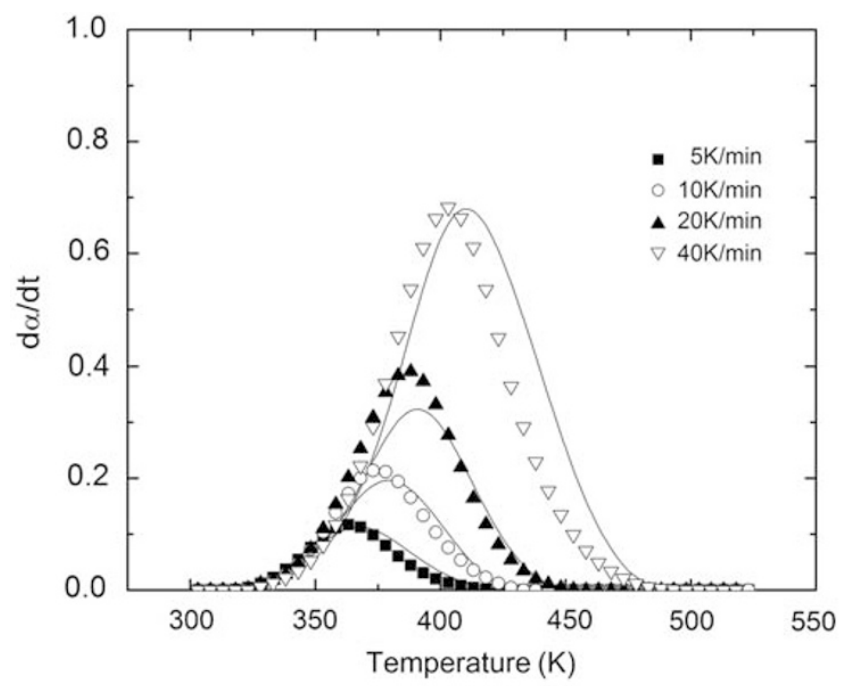

Figure 14 Comparison of experimental (symbols) and calculated (full lines) differential scanning calorimetry curves for the sample 2/diglycidyl ether of bisphenol A system.

The accuracy of the kinetic model proposed using the ŠestákBerggren equation was verified by plotting $\mathrm{d} \alpha / \mathrm{d} t$ versus temperature (experimental curves), using the data listed in Table 3, and compared with the curves obtained by computational processing of thermograms (calculated curves). An example is given in Figure 14 for the sample 2/DGEBA system. It was found that the two-parameter Šesták-Berggren model describes the studied curing process well.

\section{CONCLUSIONS}

The epoxy-cured material obtained by using $\mathrm{C}_{21}$-based polyamides had better tensile strength, flexural strength and flexural modulus values than those cured by $\mathrm{C}_{36}$-based polyamides. In addition, the thermal properties of the $\mathrm{C}_{21}$-based polyamide-cured material are superior to those obtained from $\mathrm{C}_{36}$-based polyamides with regard to glass transition temperature and thermal deformation temperature.

The curing kinetics of DGEBA in the presence of $\mathrm{C}_{21}$-based polyamides were examined by DSC at various heating rates. The $E_{\mathrm{a}}$ values of samples 1-3 determined by the iso-conversional method were 52.4, 55.4 and $54.4 \mathrm{~kJ} \mathrm{~mol}^{-1}$. The values of $E_{\mathrm{a}}$ are dependent on the amine values of polyamides. The $E_{\mathrm{a}}$ value of the curing reaction decreased as the primary amine values of curing agents increased. It was established that the two-parameter autocatalytic model (the
Šesták-Berggren equation) is suitable for describing the studied curing process. The kinetic parameters that were experimentally determined were used to calculate theoretical DSC curves. These showed a good agreement with experimental data.

\section{ACKNOWLEDGEMENTS}

This study was supported by the Key Technology R\&D Program of China (program number: 2007BAD41B06) and by the Project of the Agricultural Foundation of China (2007GB24320422).

Ward, B. F., Force, C. G., Bills, A. M. \& Woodward, F. E. Preparation and surface-active properties of the sodium soaps, mono-and diethanolamides and diol and triol sulfates of cycloaliphatic $\mathrm{C}_{21}$ Di- and $\mathrm{C}_{22}$ tricarboxylic acids. J. Am. Oil chem. Soc. 52, 219 (1975).

2 Vijayalakshmi, P., Subbarao, R. \& Lakshminarayana, G. Kinetics of reaction of $\mathrm{C}_{21}$ cycloaliphatic dicarboxylic acid and ethylenediamine. J. Am. Oil chem. Soc. 65, 939 (1988).

3 Tramount, Y. A. \& Charleston, S. C. Method for production of dicarboxylic acid and lactone. U.S. Patent: 5136055 (1992).

4 Vijayalakshmi, P., Chandrasekhara Rao, T., Kale, V., Balakrishna, R. S. \& Subbarao, R. Reactive polyamides from cycloaliphatic $\mathrm{C}_{21}$ dicarboxylic acid and their evaluation as epoxy curing agents. Polymer 33, 3252 (1992)

5 Zhang, Z., Liang, G., Ren, P. \& Wang, J. Curing behavior of Epoxy/POSS/DDS hybrid systems. Polym. Composite. 29, 77 (2007).

6 Omrani, A., Simon, L. C., Rostami, A. A. \& Ghaemy, M. Cure kinetics, dynamic mechanical and morphological properties of epoxy resin-Im6NiBr2 system. Eur. Polym. J. 44, 769 (2008).

7 Dai, Z., Li, Y., Yang, S., Zong, C., Lu, X. \& Xu, J. Preparation, curing kinetics, and thermal properties of bisphenol fluorene epoxy resin. J. Appli. Polym. Sci. 106, 1476 (2007).

8 Teo, J. K. H., Teo, K. C., Pan, B., Xiao, Y. \& Lu, X. Epoxy/polyhedral oligomeric silsesquioxane (POSS) hybrid networks cured with an anhydride: cure kinetics and thermal properties. Polymer 48, 5671 (2007)

9 Ngo, T. D., Tonthat, M. T., Hoa, S. V. \& Cole, K. C Curing kinetics and mechanical properties of epoxy nanocomposites based on different organoclays. Polym. Eng. Sci. 47, 649 (2007).

10 Chiou, P. L. \& Letton, A. Modelling the chemorheology of an epoxy resin system exhibiting complex curing behavior. Polymer 33, 3925 (1992).

11 Deng, Y. \& Martin, G. C. Diffusion and diffusion-controlled kinetics during epoxy-amine cure. Macromolecules 27, 5147 (1994).

12 Rohr, D. F. \& Klein, M. T. Modeling diffusion and reaction in epoxy-amine linear polymerization kinetics. Ind. Eng. Chem. Res. 27, 1361 (1988).

13 O' Brien, D. J. \& White, S. R. Cure kinetics, gelation, and glass transition of a bisphenol F epoxide. Polym. Eng. Sci. 43, 863 (2003).

14 Wang, C. S. \& Lin, C. H. Novel phosphorus containing epoxy resins II. curing kinetics. Polymer 41, 8579 (2000).

15 Salvador, M. \& Málek, J. Kinetic analysis of curing reaction in an epoxy resin. Thermochim. Acta. 228, 47 (1993).

16 Málek, J. The kinetic analysis of non iso-thermal data. Thermochim. acta. 200, 257 (1992).

17 Sbirrazzuoli, N., Girault, Y. \& Eligant, L. The malek method in the kinectic study of polymerization by DSC. Thermochim. Acta. 249, 179 (1995).

18 Roșu, D., Cașcaval, C. N. \& Mustață, F. Cure kinetics of epoxy resins studied by nonisothermal DSC data. Thermochim. Acta. 383, 257 (2002).

19 Yao, L., Deng, J., Qu, B. \& Shi, W. Cure kinetics of DGEBA with hyperbranched Poly (3hydroxyphenyl) phosphate as curing agent studied by non-isothermal DSC. Chem. Res. Chinese U. 22, 118 (2006).

20 Málek, J. A computer program for kinetic analysis of non-isothermal thermoanalytical data. Thermochim. Acta. 138, 337 (1989).

21 Xia, J., Wang, D., Nie, X. \& Yang, X. Method for preparation of low molecular weight polyamides from tung oil, C. N. Patent: 1631938 (2006).

22 Barret, K. E. J. Determination of rates of thermal decomposition of polymerization initiators with a differential scanning calorimeter. J. Appl. Polym. Sci. 11, 1617 (1967).

23 Kissinger, H. E. Reaction kinetics in differential thermal analysis. Anal. Chem. 29, 1702 (1957).

24 Senum, G. I. \& Yang, R. T. Rational approximations of the integral of the arrhenius function. J. Thermal. Anal. 11, 445 (1977).

25 Málek, J. Kinetic analysis of crystallization processes in amorphous materials. Thermochim. Acta. 355, 239 (2000).

26 Šesták, J. \& Berggren, G. Study of the kinetics of the mechanism of solid-state reactions at increasing temperatures. Thermochim. Acta. 1, 1 (1971). 